\title{
PSYCHIATRIC ILLNESS AMONG SEXUAL RAPISTS IN BULGARIA
}

$\underline{\text { L. Tumbev }}^{1}$, P. Chumpalova ${ }^{1}$, M. Stoimenova-Popova ${ }^{1}$, K. Stoychev ${ }^{1}$, P. Popov $^{2}$, V. Valtchev ${ }^{3}$. E. Krasteva $^{4}$

${ }^{1}$ Medical University, Psychiatry and Medical Psychology, Pleven, Bulgaria.

${ }^{2}$ Ministry of Health, National Center for Addictions, Sofia, Bulgaria.

${ }^{3}$ National Sports Academy, Department of Biochemistry and Physiology, Sofia, Bulgaria

${ }^{4}$ UMHAT "Dr. Georgi Stranski", Mental Health Center, Pleven, Bulgaria

Key words: sexual rapists, psychiatric illness

Objectives: Research on psychiatric morbidity in sexual offenders has mostly been based on small, selected samples.

Background: The aim of this study was to evaluate the frequency of psychiatric illness among sexual crime offenders in North Central Region in Bulgaria

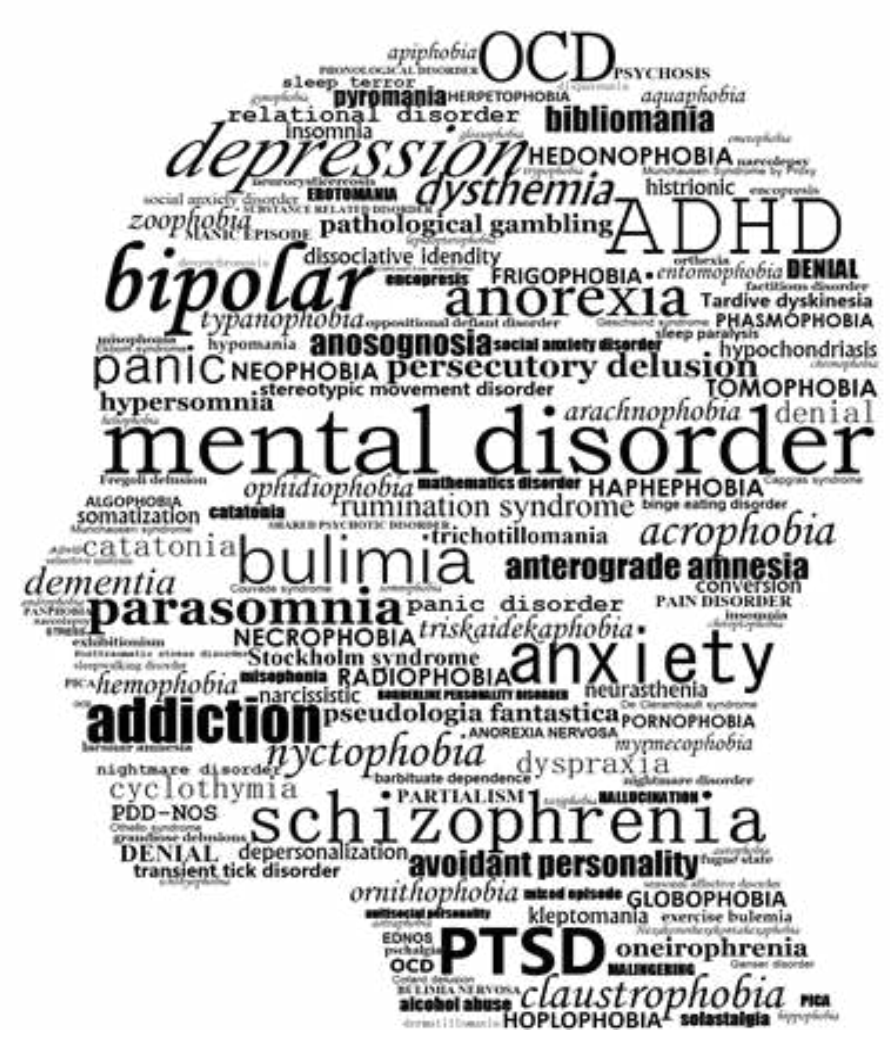

Materials and Methods: We investigated 66 people convicted of sexual offenses. All investigated persons were subjected to a psychiatric-psychological judicial expertise from the period of 5 years. This research uses sociological methods of gathering informationinterviews, retrospective researches of the available medical documentation. A statistician conducts data research analysis, using specialised software statistical packages for STATGRAPHICS; SPSS and EXCEL for Windows. The significance of the results, findings and conclusions determine $\mathrm{p}<0,05$.

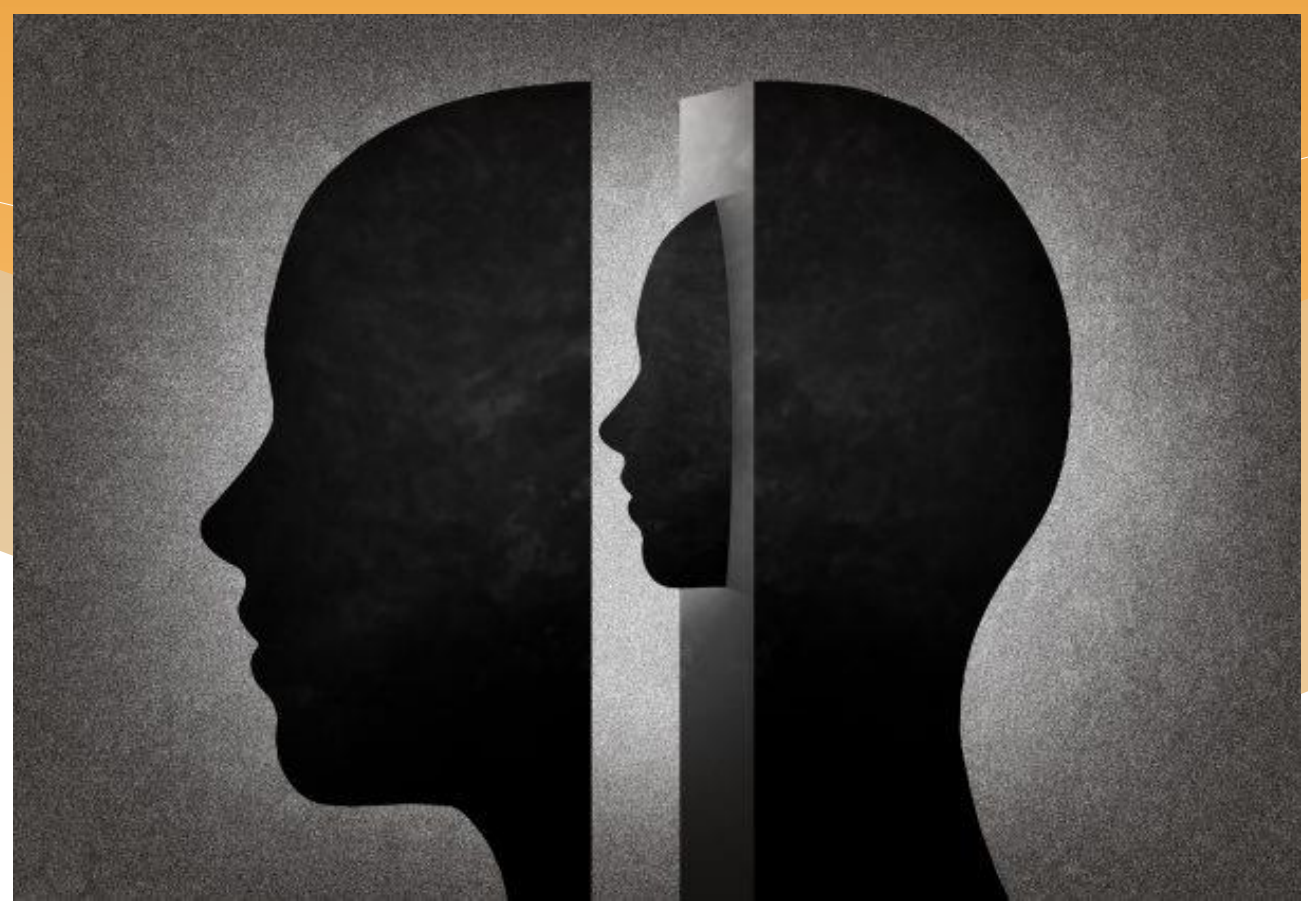

Results and Conclusions: The majority of the participants are from the age groups between 15-24 (27\%) and 45-54 years old (27\%). 76 $\%$ of offenders don't have a family history for mental illness. Current data reports statistically significant difference between personality pathology - $81 \%(\mathrm{p}<0,05)$ and other mental disorders. Alcohol use - $27 \%$, intellectual disability $-18 \%$ and organic brain pathology in $13 \%$. From group with mental disorders, 36 $\%$ are diagnosed with more than one mental illness. None of the convicts has anamnesis containing an acute psychotic episode or an episode of chronic schizophrenia and affective disorders. $27 \%$ of the sexual offenders have been in a state of alcohol intoxication during the criminal act. The individuals that have an anamnesis of predisposition for substance addiction/abuse from first-degree relatives are $12 \%$. Most often mentally illnesses are personality disorders 